\title{
Impact of Perioperative Blood Transfusion on Postoperative Complications and Prognosis of Gastric Adenocarcinoma Patients with Different Preoperative Hemoglobin Value
}

\author{
Lian Xue, ${ }^{1,2}$ Xiao-Long Chen,,2 Zhang Wei-Han,, ${ }^{1,2}$ Kun Yang, ${ }^{1,2}$ Xin-Zu Chen, ${ }^{1,2}$ \\ Bo Zhang, ${ }^{1}$ Zhi-Xin Chen, ${ }^{1}$ Jia-Ping Chen, ${ }^{1}$ Zong-Guang Zhou, ${ }^{1,3}$ and Jian-Kun Hu ${ }^{1,2}$ \\ ${ }^{1}$ Department of Gastrointestinal Surgery, West China Hospital, Sichuan University, No. 37 Guo Xue Xiang Street, \\ Chengdu, Sichuan 610041, China \\ ${ }^{2}$ Laboratory of Gastric Cancer, State Key Laboratory of Biotherapy, West China Hospital, Sichuan University, \\ No. 37 Guo Xue Xiang Street, Chengdu, Sichuan 610041, China \\ ${ }^{3}$ Laboratory of Digestive Surgery, State Key Laboratory of Biotherapy, West China Hospital, Sichuan University, \\ No. 37 Guo Xue Xiang Street, Chengdu, Sichuan 610041, China
}

Correspondence should be addressed to Jian-Kun Hu; hujiankunwestchina@126.com

Received 25 June 2015; Revised 15 September 2015; Accepted 15 September 2015

Academic Editor: Fausto Rosa

Copyright (C) 2016 Lian Xue et al. This is an open access article distributed under the Creative Commons Attribution License, which permits unrestricted use, distribution, and reproduction in any medium, provided the original work is properly cited.

Background. The impact of perioperative blood transfusion on the prognosis of gastric adenocarcinoma patients is still controversial. The aim of this study was to elucidate the impact of perioperative blood transfusion on postoperative complications and prognosis of patients who underwent gastrectomy for gastric adenocarcinoma with different levels of preoperative hemoglobin value (POHb). Method. From 2003 to 2011, 1199 patients who underwent curative gastrectomy were retrospectively enrolled and followed up to December 2014. Clinicopathological features and survival outcomes were compared between transfused and nontransfused patients. Results. In this study, transfused patients had more postoperative complications than nontransfused ones $(P=0.002)$. In survival analysis, the difference was not significant between transfused and nontransfused patients with POHb between 70 and $100 \mathrm{~g} / \mathrm{L}(P=0.191)$. However, in patients with POHb $>100 \mathrm{~g} / \mathrm{L}$, transfused patients had significantly worse prognosis $(P<0.001)$, especially in TNM III stage patients $(P=0.002)$. And intraoperative blood transfusion predicted poor prognosis $(P=0.001)$. Conclusion. Perioperative blood transfusion might lead to poor survival in gastric adenocarcinoma patients with $\mathrm{POHb}>100 \mathrm{~g} / \mathrm{L}$ and transfused patients had more postoperative complications; thus it is better to refrain from unnecessary perioperative blood transfusion especially intraoperative transfusion.

\section{Introduction}

Gastric adenocarcinoma (GAC) is one of the most common malignant cancers in the world [1]. Surgery is considered to be the main treatment for GAC. Patients with cancers were prone to have anemia, and radical resection with extended lymphadenectomy might cause much blood loss during surgery; thus patients with low hemoglobin $(\mathrm{Hb})$ value might receive perioperative blood transfusion.

Whether perioperative blood transfusion impacted on the prognosis of patients with cancer was still under debate. Some studies reported that blood transfusion was related to poor prognosis of patients with colorectal cancer, renal cell carcinoma, lung cancer, and breast cancer [2-6]. The possible reason might be that blood transfusion could cause immunomodulation, which decreased the activities of natural killer cells and increased the activities of regulatory $\mathrm{T}$ cells [7]. However, other studies held the opposite opinion, indicating that blood transfusion did not affect patient's outcomes $[8,9]$.

With respect to gastric adenocarcinoma, several researches had been carried out in order to find out the relationship among perioperative blood transfusion, postoperative complications, and prognosis, but it still remained 
controversial. Although some reports did not support the fact that blood transfusion was related to poor prognosis, others claimed that it did exist [10-14]. Some reports showed that transfused patients had more postoperative complications $[13,15]$.

In China, according to the clinical guideline of blood transfusion, patients with $\mathrm{POHb}$ lower than $70 \mathrm{~g} / \mathrm{L}$ should be transfused, and there is no need of transfusion for patients with $\mathrm{POHb}>100 \mathrm{~g} / \mathrm{L}$ [16]. However, there were few studies discussing prognosis of perioperative transfused patients with cancer grouped by different POHb. In our study, we divided the patients into different groups according to their $\mathrm{POHb}$ and tried to find out the relationship among blood transfusion, postoperative complications, and survival of patients in these different groups.

\section{Methods}

The West China Hospital research ethics committee approved retrospective analysis of anonymous data. Signed patient informed consent was waived per the committee approval, because it was a retrospective analysis.

2.1. Patients. From January 2003 to April 2011, 1199 patients who underwent curative gastrectomy with $\mathrm{R} 0$ resection for gastric adenocarcinoma at Department of Gastrointestinal Surgery, West China Hospital, Sichuan University, were enrolled in our study. Patients with distant metastases, neoadjuvant chemoradiotherapy, previous neoplastic diseases, and hematological pathologies were excluded from our study. We divided patients into three groups according to their POHb value: Group 1: patients with $\mathrm{POHb} \leq 70 \mathrm{~g} / \mathrm{L}$; Group 2: patients with $\mathrm{POHb}$ between 70 and $100 \mathrm{~g} / \mathrm{L}$; Group 3: patients with $\mathrm{POHb}>100 \mathrm{~g} / \mathrm{L}$. In Group 2 and Group 3, patients were divided into two subgroups according to whether they had perioperative blood transfusion. And all the patients in Group 1 had received blood transfusion. The clinicopathological features such as tumor size, tumor location, differentiation grade, and pathological TNM stage were recorded according to Japanese classification of gastric carcinoma by JGCA [17]. Other variables including operation time, intraoperative blood loss, and postoperative complications were also analyzed. Clinicopathological features and overall survival rates were compared among these groups.

2.2. Surgical Treatment. Gastrectomy plus lymphadenectomy was the mainstay treatment for patients with gastric adenocarcinoma. Patients with early gastric adenocarcinoma underwent $\mathrm{D} 1 / \mathrm{D} 1+$, while patients with advanced gastric adenocarcinoma underwent D2/D2+ lymphadenectomy. All the operations were performed by expertise of surgeons specialized in gastrointestinal surgery according to Japanese Gastric Cancer Treatment Guidelines [18].

2.3. Perioperative Blood Transfusions. Perioperative blood transfusion was defined as either whole blood or packed red blood cells administered within 14 days before surgery, during surgery, or 14 days after surgery [14]. Usually, POHb $\leq$ $70 \mathrm{~g} / \mathrm{L}$ and significant intraoperative blood loss were general indications for blood transfusion. The amount and time of perioperative blood transfusion were recorded.

2.4. Follow-Up. Regular outpatient visit was the first choice for follow-up, while telephones and mails were adopted as two main supplementary follow-up methods. Follow-up information was updated until December 2014. The main reasons for the loss of follow-up were the changes of phone number or home address and refusal of reexamination in our hospital.

2.5. Statistical Analysis. All the statistical analyses were performed with the statistical software SPSS 19.0 (SPSS, Chicago, Illinois, USA). All continuous values were presented as mean \pm standard deviation (SD). Unordered categorical variable and ranked data were analyzed through chi-square test and rank sum test, respectively. Student's $t$-test was used to analyze continuous data if variance was homogeneity and distribution was normal. If not, rank sum test was used. Multivariate logistic regression analysis was performed to identify risk factors for need of perioperative blood transfusion. Survival curves were computed using Kaplan-Meier and compared by means of log-rank test. Multivariate analysis was performed by Cox regression test to find out independent prognostic factors. $P$ value $<0.05$ was considered statistically significant.

\section{Results}

3.1. Demography of Patients. In this study, 1199 patients with different $\mathrm{POHb}$ were included, with 345 (28.8\%) patients receiving perioperative blood transfusion and $854(71.2 \%)$ receiving no transfusion. 54 (4.5\%) patients were in $\mathrm{POHb} \leq$ $70 \mathrm{~g} / \mathrm{L}$ group while 257 (21.4\%) ones were in POHb between 70 and $100 \mathrm{~g} / \mathrm{L}$ group and $888(74.1 \%)$ patients in $\mathrm{POHb}$ $>100 \mathrm{~g} / \mathrm{L}$ group. Among transfused patients, 177 (51.3\%) patients received less than 2 units $(200 \mathrm{~mL} / \mathrm{unit})$ of blood transfusion, $94(27.2 \%)$ patients received 2-4 units, and $74(21.5 \%)$ received more than 4 units. Ninety-six $(27.8 \%)$ patients underwent preoperative transfusion; $210(60.9 \%)$ ones underwent intraoperative transfusion while 39 (11.3\%) patients underwent postoperative transfusion.

Comparisons of clinicopathological features between transfused and nontransfused patients were shown in Table 1. Of all the patients, transfused ones had significantly more combined organ resections $(P<0.001)$, more patients with open surgery $(P<0.001)$, and more intraoperative blood loss $(P<0.001)$. Postoperative complications seemed to occur more frequently in transfused patients $(P=0.002)$ especially pulmonary infection (transfused $18.8 \%$ versus nontransfused 13.7\%). Table 2 showed the comparison between transfused and nontransfused patients in $\mathrm{POHb}$ between 70 and $100 \mathrm{~g} / \mathrm{L}$ or $\mathrm{POHb}>100 \mathrm{~g} / \mathrm{L}$ groups. Clinicopathological characteristics were similar with regard to sex, TNM stage, differentiation grade, macroscopic type, and tumor size in transfused and nontransfused subgroups of patients with POHb between 70 and $100 \mathrm{~g} / \mathrm{L}$ (all $P>0.05$ ). However, in the patients with $\mathrm{POHb}>100 \mathrm{~g} / \mathrm{L}$ group, transfused patients had more advanced TNM stage $(P<0.001)$, larger tumor size 
TABLE 1: Comparison of clinicopathological features of all transfused and nontransfused patients.

\begin{tabular}{|c|c|c|c|c|}
\hline & Categories & $\begin{array}{c}\text { Transfused } \\
n=345(\%)\end{array}$ & $\begin{array}{c}\text { Nontransfused } \\
n=854(\%)\end{array}$ & $P$ value \\
\hline Age & Mean \pm SD & $58.4 \pm 11.7$ & $55.9 \pm 11.5$ & 0.001 \\
\hline \multirow{2}{*}{ Gender } & Male & $244(70.7)$ & $605(70.8)$ & \multirow{2}{*}{0.967} \\
\hline & Female & $101(29.3)$ & $245(29.2)$ & \\
\hline \multirow{2}{*}{ Combined organ resection } & Yes & $41(11.9)$ & $31(3.6)$ & \multirow{2}{*}{$<0.001$} \\
\hline & No & $304(88.1)$ & $823(96.4)$ & \\
\hline \multirow{3}{*}{ Type of gastrectomy } & DG & $193(55.9)$ & $519(60.8)$ & \multirow{3}{*}{0.055} \\
\hline & TG & $86(24.9)$ & $160(18.7)$ & \\
\hline & PG & $66(19.2)$ & $175(20.5)$ & \\
\hline \multirow{2}{*}{ Operation approach } & Open surgery & $325(94.2)$ & $725(84.9)$ & \multirow{2}{*}{$<0.001$} \\
\hline & Laparoscopic assisted & $20(5.8)$ & $129(15.1)$ & \\
\hline \multirow{2}{*}{ Concomitant diseases } & Yes & $182(52.8)$ & $403(47.2)$ & \multirow{2}{*}{0.081} \\
\hline & No & $163(47.2)$ & $451(52.8)$ & \\
\hline \multirow{4}{*}{ Longitudinal location } & $\mathrm{U}$ & $72(20.9)$ & $221(25.9)$ & \multirow{4}{*}{0.004} \\
\hline & M & $63(18.3)$ & $102(11.9)$ & \\
\hline & $\mathrm{L}$ & $202(58.6)$ & $523(61.2)$ & \\
\hline & Whole & $8(2.2)$ & $8(1.0)$ & \\
\hline \multirow{2}{*}{ Differentiation grade } & Well/moderate & $48(13.9)$ & $171(20.0)$ & \multirow{2}{*}{0.013} \\
\hline & Poor/undifferentiated & $297(86.1)$ & $683(80.0)$ & \\
\hline \multirow{2}{*}{ Macroscopic type } & Types $0-2$ & $210(60.9)$ & $569(66.6)$ & \multirow{2}{*}{0.058} \\
\hline & Types 3-4 & $135(39.1)$ & $285(33.4)$ & \\
\hline \multirow{3}{*}{ Tumor size $(\mathrm{cm})$} & Mean \pm SD & $5.7 \pm 2.6$ & $4.6 \pm 2.5$ & $<0.001$ \\
\hline & $\leq 4.5$ & $120(34.8)$ & $461(54.0)$ & \multirow{2}{*}{$<0.001$} \\
\hline & $>4.5$ & $225(65.2)$ & $393(46.0)$ & \\
\hline \multirow{4}{*}{ T stage } & $\mathrm{T} 1$ & $28(8.1)$ & $192(22.5)$ & \multirow{4}{*}{$<0.001$} \\
\hline & $\mathrm{T} 2$ & $37(10.7)$ & $121(14.2)$ & \\
\hline & $\mathrm{T} 3$ & $14(4.1)$ & $44(5.2)$ & \\
\hline & $\mathrm{T} 4$ & $266(77.1)$ & $497(58.1)$ & \\
\hline \multirow{5}{*}{$\mathrm{N}$ stage } & No & $84(24.3)$ & $319(37.4)$ & \multirow{5}{*}{$<0.001$} \\
\hline & N1 & $69(20.0)$ & $154(18.0)$ & \\
\hline & $\mathrm{N} 2$ & $66(19.1)$ & $168(19.7)$ & \\
\hline & $\mathrm{N} 3 \mathrm{a}$ & $90(26.1)$ & $157(18.4)$ & \\
\hline & $\mathrm{N} 3 \mathrm{~b}$ & $37(10.5)$ & $56(6.5)$ & \\
\hline \multirow{2}{*}{ TNM stage } & $\mathrm{I} / \mathrm{II}$ & $108(31.3)$ & $410(48.0)$ & \multirow{2}{*}{$<0.001$} \\
\hline & III & $237(68.7)$ & $444(52.0)$ & \\
\hline Operation time (min) & Mean \pm SD & $241.0 \pm 61.9$ & $232.8 \pm 49.9$ & 0.169 \\
\hline Intraoperative blood loss $(\mathrm{mL})$ & Mean \pm SD & $528.7 \pm 282.2$ & $414.2 \pm 194.3$ & $<0.001$ \\
\hline & Stomach without tension & $2(0.6)$ & $19(2.2)$ & \\
\hline & Wound infection & $7(2.0)$ & $10(1.2)$ & \\
\hline & Anastomotic leakage & $8(2.3)$ & $6(0.7)$ & \\
\hline Postoperative complications & Bleeding & $9(2.6)$ & $3(0.4)$ & 0.002 \\
\hline & Pulmonary infection & $65(18.8)$ & $117(13.7)$ & \\
\hline & Others & $14(4.1)$ & $16(1.9)$ & \\
\hline & Total patients & $82(23.8)$ & $152(17.8)$ & \\
\hline Postoperative hospital stay & Mean \pm SD & $12.4 \pm 10.6$ & $11.7 \pm 9.8$ & 0.261 \\
\hline
\end{tabular}

SD: standard deviation, DG: distal gastrectomy, TG: total gastrectomy, PG: proximal gastrectomy, U: upper, M: middle, and L: lower. 


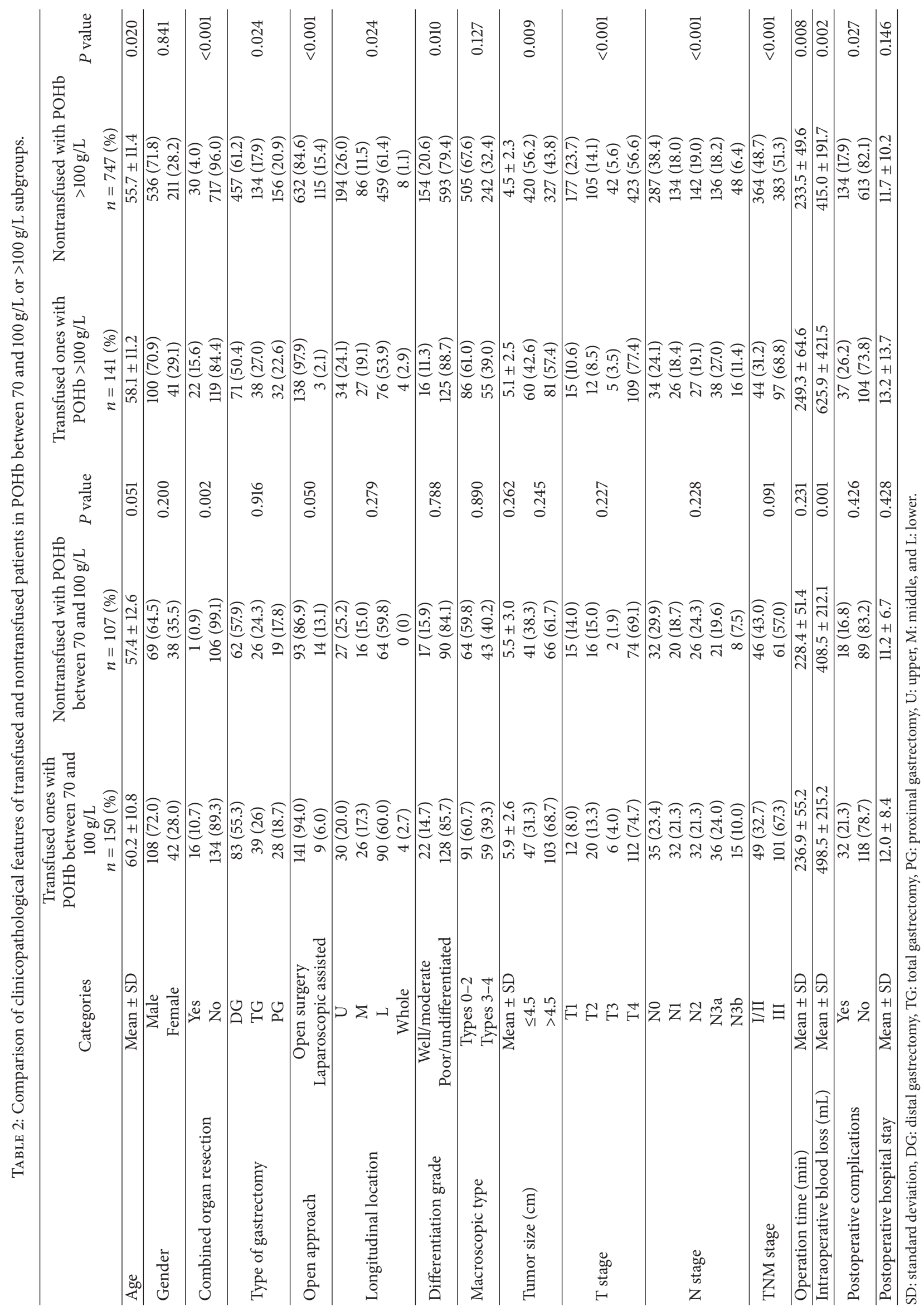


TABLE 3: Multivariate analysis of risk factors for blood transfusion in patients with POHb between 70 and $100 \mathrm{~g} / \mathrm{L}$.

\begin{tabular}{|c|c|c|c|c|c|}
\hline & Parameter estimate & SE & Adjusted OR & $95 \% \mathrm{CI}$ & $P$ value \\
\hline Age & & & & & 0.073 \\
\hline Gender & & & & & 0.097 \\
\hline Macroscopic type & & & & & 0.256 \\
\hline Differentiation grade & & & & & 0.786 \\
\hline Tumor size & & & & & 0.302 \\
\hline TNM & & & & & 0.438 \\
\hline Intraoperative blood loss & -0.002 & 0.001 & 0.998 & $0.997-0.999$ & 0.002 \\
\hline Combined organ resection & 2.540 & 1.047 & 12.674 & $1.629-98.640$ & 0.015 \\
\hline
\end{tabular}

Adjusted OR estimated by the Cox model.

95\% CI: 95\% confidence interval, OR: odd ratio, and SE: standard error.

TABLE 4: Multivariate analysis of risk factors for blood transfusion in patients with POHb >100 g/L.

\begin{tabular}{|c|c|c|c|c|c|}
\hline & Parameter estimate & SE & Adjusted OR & $95 \% \mathrm{CI}$ & $P$ value \\
\hline Age & 0.799 & 0.322 & 2.224 & $1.184-4.178$ & 0.013 \\
\hline Gender & & & & & 0.481 \\
\hline Macroscopic type & & & & & 0.829 \\
\hline Differentiation grade & & & & & 0.113 \\
\hline Tumor size & & & & & 0.957 \\
\hline Type of gastrectomy & & & & & 0.402 \\
\hline TNM stage & -1.028 & 0.367 & 0.358 & $0.174-0.734$ & 0.005 \\
\hline Longitudinal location & & & & & 0.867 \\
\hline Intraoperative blood loss & -0.003 & 0.001 & 0.997 & $0.995-0.998$ & $<0.001$ \\
\hline Combined organ resection & 1.105 & 0.518 & 3.019 & $1.094-8.333$ & 0.033 \\
\hline
\end{tabular}

Adjusted OR estimated by the Cox model.

95\% CI: 95\% confidence interval, OR: odd ratio, and SE: standard error.

( $P=0.009)$, more poor differentiated grade $(P=0.010)$, and more postoperative complications $(P=0.027)$.

3.2. Risk Factors for Blood Transfusion. To identify risk factors for blood transfusion, univariate and multivariate analyses were performed in each group, respectively. The results of multivariate analysis of different groups were shown in Tables 3 and 4. In logistic regression analysis, risk factors for blood transfusion in patients with $\mathrm{POHb}$ between 70 and $100 \mathrm{~g} / \mathrm{L}$ were significantly associated with intraoperative blood loss $(P=0.002)$ and combined organ resection $(P=0.015)$. However, risk factors for blood transfusion in patients with $\mathrm{POHb}>100 \mathrm{~g} / \mathrm{L}$ were associated with age $(P=0.013)$, combined organ resection $(P=0.033)$, TNM stage $(P=0.005)$, and intraoperative blood loss $(P<0.001)$.

3.3. Survival Analyses. Finally, 999 patients (83.3\%) were followed up and included in survival analysis. The median survival time of transfused and nontransfused group was 46.3 (0.07-141.9) months and 111.5 (0-141.9) months, respectively. Three-year survival rates were $51 \%$ and $61 \%$ in transfused and nontransfused patients with POHb between 70 and $100 \mathrm{~g} / \mathrm{L}$, respectively. In transfused and nontransfused patients with $\mathrm{POHb}>100 \mathrm{~g} / \mathrm{L}$, the 3 -year survival rates were $44 \%$ and $65 \%$, respectively. In univariate analysis, age $(P=0.001)$, type of gastrectomy $(P<0.001)$, combined organ resections $(P=$ $0.003)$, longitudinal location $(P<0.001)$, differentiation grade $(P=0.009)$, macroscopic type $(P<0.001)$, tumor size $(P<0.001)$, pT stage $(P<0.001)$, pN stage $(P<$ $0.001)$, pTNM stage $(P<0.001)$, and perioperative blood transfusion $(P<0.001)$ were associated with overall survival in all patients with gastrectomy in our study (Table 5). The multivariate analysis revealed that age $(P=0.005)$, tumor size $(P<0.001)$, and TNM stage $(P<0.001)$ were independent prognostic factors in gastric adenocarcinoma patients (Table 5).

3.4. Subgroup Analyses. Of all patients, Kaplan-Meier curve showed that transfused patients had significantly worse prognosis than nontransfused patients (Figure 1(a), $P<0.001$ ). Nontransfused patients with $\mathrm{POHb}>100 \mathrm{~g} / \mathrm{L}$ had better survival outcomes among the subgroups we divided in this study (Figure $1(\mathrm{~b}), P=0.001$ ). When comparing prognosis between transfused and nontransfused patients in $\mathrm{POHb}$ between 70 and $100 \mathrm{~g} / \mathrm{L}$ and $\mathrm{POHb}>100 \mathrm{~g} / \mathrm{L}$ groups, respectively, we found out that there was no significant difference in prognosis between transfused and nontransfused ones in POHb between 70 and $100 \mathrm{~g} / \mathrm{L}$ group $(P=0.191$, Figure $1(\mathrm{c}))$. However, in $\mathrm{POHb}>100 \mathrm{~g} / \mathrm{L}$ group, the survival was significantly better in the nontransfused group than transfused group $(P<0.001$, Figure $1(\mathrm{~d}))$. We further divided patients according to their TNM stage (I/II stage; III stage) in POHb $>100 \mathrm{~g} / \mathrm{L}$ subgroup, and constituent ratios of differentiation grade, macroscopic type, and tumor size between these two 
TABLE 5: Univariate and multivariate Cox analysis for prognostic factors.

\begin{tabular}{|c|c|c|c|c|c|c|}
\hline \multirow{2}{*}{ Risk factors } & \multirow{2}{*}{ Categories } & \multirow{2}{*}{3 -year overall survival rate (\%) } & \multirow{2}{*}{ Univariate analysis $P$ value } & \multicolumn{3}{|c|}{ Multivariate analysis } \\
\hline & & & & $P$ value & OR & $95 \% \mathrm{CI}$ \\
\hline \multirow{2}{*}{ Age (years) } & $\leq 60$ & 64 & \multirow{2}{*}{0.001} & \multirow{2}{*}{0.005} & \multirow{2}{*}{1.308} & \multirow{2}{*}{$1.084-1.579$} \\
\hline & $>60$ & 56 & & & & \\
\hline \multirow{2}{*}{ Gender } & Male & 59 & \multirow{2}{*}{0.191} & & & \\
\hline & Female & 63 & & & & \\
\hline \multirow{3}{*}{$\begin{array}{l}\text { Type of } \\
\text { gastrectomy }\end{array}$} & DG & 66 & \multirow{3}{*}{$<0.001$} & \multirow{3}{*}{0.254} & & \\
\hline & TG & 48 & & & & \\
\hline & PG & 54 & & & & \\
\hline \multirow{2}{*}{$\begin{array}{l}\text { Combined organ } \\
\text { resection }\end{array}$} & Yes & 44 & \multirow{2}{*}{0.003} & \multirow{2}{*}{0.104} & & \\
\hline & No & 61 & & & & \\
\hline \multirow{4}{*}{$\begin{array}{l}\text { Longitudinal } \\
\text { location }\end{array}$} & $\mathrm{U}$ & 53 & \multirow{4}{*}{$<0.001$} & \multirow{4}{*}{0.934} & & \\
\hline & M & 59 & & & & \\
\hline & $\mathrm{L}$ & 64 & & & & \\
\hline & Whole & 17 & & & & \\
\hline \multirow{2}{*}{$\begin{array}{l}\text { Differentiation } \\
\text { grade }\end{array}$} & Well/ moderate & 70 & \multirow{2}{*}{0.009} & \multirow{2}{*}{0.078} & & \\
\hline & Poor/undifferentiated & 58 & & & & \\
\hline \multirow{2}{*}{ Macroscopic type } & Types $0-2$ & 68 & \multirow{2}{*}{$<0.001$} & \multirow{2}{*}{0.083} & & \\
\hline & Types 3-4 & 45 & & & & \\
\hline \multirow{2}{*}{ Tumor size } & $\leq 4.5 \mathrm{~cm}$ & 72 & $<0.001$ & $<0.001$ & 1.460 & $1.190-1.791$ \\
\hline & $>4.5 \mathrm{~cm}$ & 48 & $<0.001$ & $<0.001$ & 1.400 & $1.170-1.78$ \\
\hline & $\mathrm{T} 1$ & 87 & & & & \\
\hline $\mathrm{T}$ stage & $\mathrm{T} 2$ & 79 & $<0.001$ & & & \\
\hline & T3 & 65 & & & & \\
\hline & $\mathrm{T} 4$ & 48 & & & & \\
\hline & No & 84 & & & & \\
\hline & N1 & 68 & & & & \\
\hline N stage & $\mathrm{N} 2$ & 51 & $<0.001$ & & & \\
\hline & N3a & 38 & & & & \\
\hline & $\mathrm{N} 3 \mathrm{~b}$ & 23 & & & & \\
\hline TNM stage & $\mathrm{I} / \mathrm{II}$ & 83 & $<0.001$ & $<0.001$ & 2.607 & $2.087-3.256$ \\
\hline RNN stage & III & 43 & 0.001 & 0.001 & 2.007 & $2.00 \%-0.250$ \\
\hline Postoperative & Yes & 52 & 0.110 & & & \\
\hline complications & No & 61 & 0.110 & & & \\
\hline Perioperative & Yes & 49 & $<0.001$ & 0.079 & & \\
\hline blood transfusion & No & 64 & & 0.078 & & \\
\hline
\end{tabular}

SD: standard deviation, DG: distal gastrectomy, TG: total gastrectomy, PG: proximal gastrectomy, U: upper, M: middle, and L: lower.

subgroups were similar. We found that, in stage I/II subgroup, the difference was not significant between transfused and nontransfused groups $(P=0.674$, Figure $2(a))$; however, in TNM stage III subgroup, survival outcome was remarkably better in nontransfused group than that in transfused group $(P=0.002$, Figure 2(b)). In addition, a dose-response relationship between the amount of transfused blood and prognosis was not recognized $(P=0.153$, Figure $2(\mathrm{c}))$, and the patients with intraoperative transfusion had obviously worse prognosis than those who had preoperative or postoperative transfusion $(P=0.001$, Figure $2(d))$.

\section{Discussion}

Variety of experiments had demonstrated that perioperative blood transfusion could result in immunological changes which might contribute to poor survival of patients $[19,20]$. Although many studies had been carried out to evaluate the influence of perioperative blood transfusion on the prognosis of gastric adenocarcinoma patients, the results were still varied. Sánchez-Bueno et al.'s study showed that perioperative blood transfusion did not influence the survival of patients with gastric adenocarcinoma [11]. A study by Moriguchi et al. 


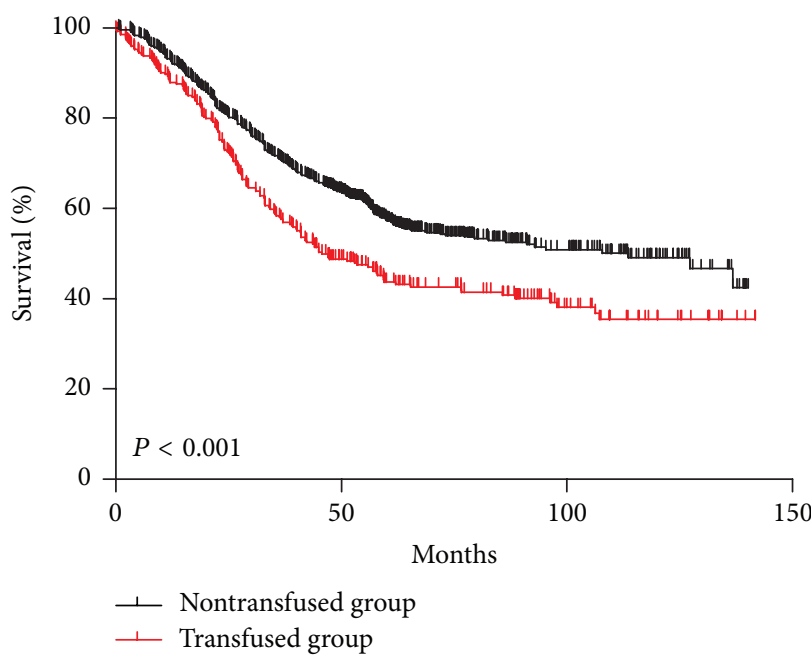

(a)

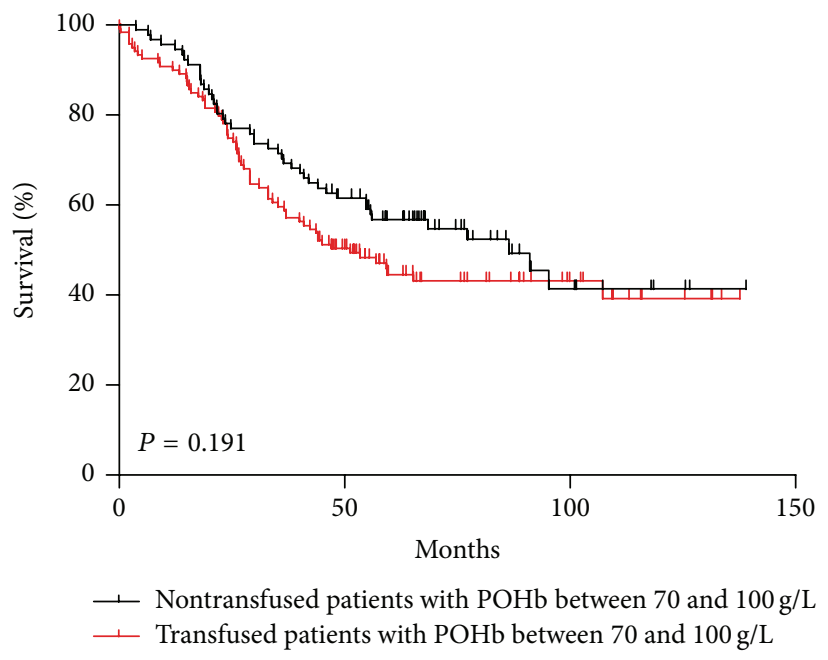

(c)

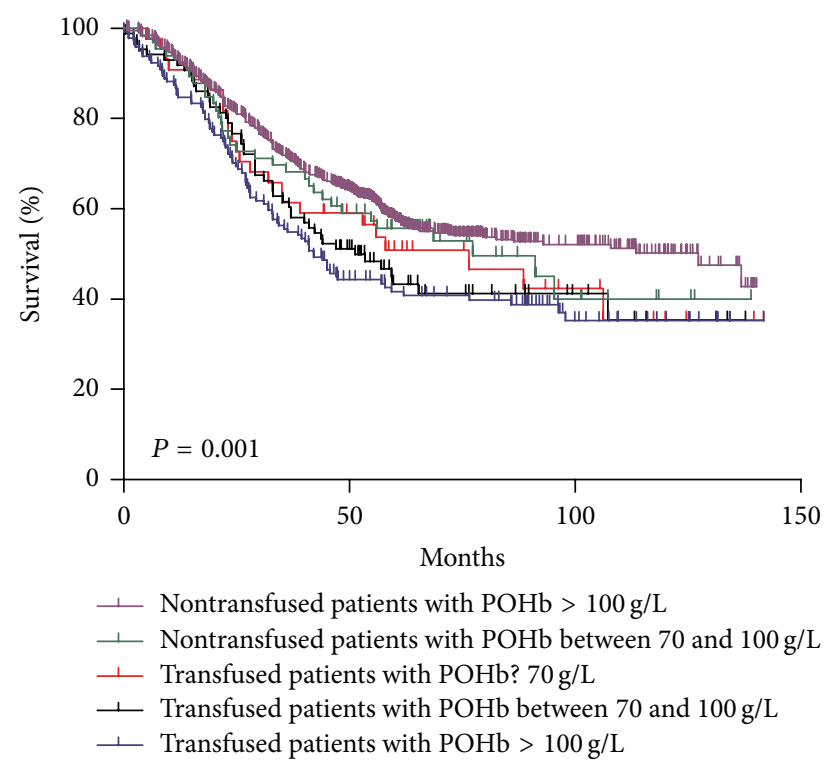

(b)

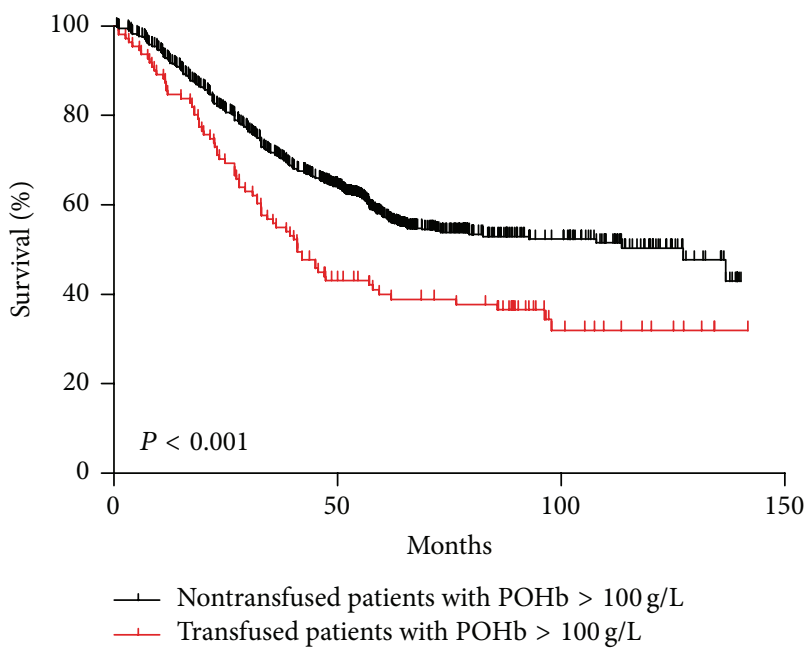

(d)

FIGURE 1: (a) Survival analysis of transfused and nontransfused patients. (b) Survival analysis of transfused and nontransfused patients with different POHb. (c) Survival analysis of transfused and nontransfused patients with POHb between 70 and 100 g/L. (d) Survival analysis of transfused and nontransfused patients with $\mathrm{POHb}>100 \mathrm{~g} / \mathrm{L}$.

also revealed the lack of any relationship between perioperative blood transfusion and survival of patients with gastric cancer [21]. On the other hand, other studies had opposite opinion that blood transfusion resulted in worse prognosis of gastric cancer patients. Ojima et al. demonstrated that perioperative blood transfusion had a negative influence on survival of patients with gastric cancer [22]. A large retrospective study with 1710 patients by Hyung et al. found that blood transfusion was an independent risk factor for recurrence and poor survival [14]. However, all the studies mentioned above discussed the relationship between perioperative blood transfusion and prognosis without concerning POHb of patients. Clinical decision for blood transfusion was driven more by hemoglobin threshold. Whether patients with $\mathrm{POHb}>70 \mathrm{~g} / \mathrm{L}$ should be transfused and whether perioperative transfusion could influence postoperative complications and prognosis of gastric adenocarcinoma patients with different POHb still remain unknown. Therefore, in our study, we divided gastric adenocarcinoma patients into different groups according to their $\mathrm{POHb}$ and tried to find out the impact of transfusion on postoperative complications and prognosis.

Our retrospective study showed that transfused patients had more postoperative complications than nontransfused ones. Other studies also demonstrated that transfused gastric cancer patients had more postoperative complications [13, 15]. We also found that pulmonary infection happened more frequently in transfused patients than nontransfused ones (transfused $18.8 \%$ versus nontransfused 13.7\%). Maybe transfusion could disturb the immune system and cause high morbidity of pulmonary infection. 


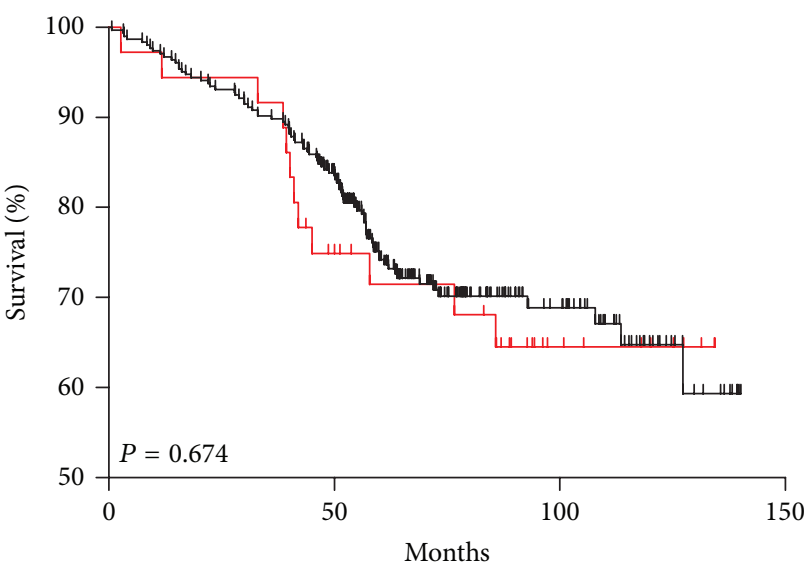

$\perp$ Nontransfused TNM I/II stage patients with POHb $>100 \mathrm{~g} / \mathrm{L}$ $\perp$ Transfused TNM I/II stage patients with POHb $>100 \mathrm{~g} / \mathrm{L}$

(a)

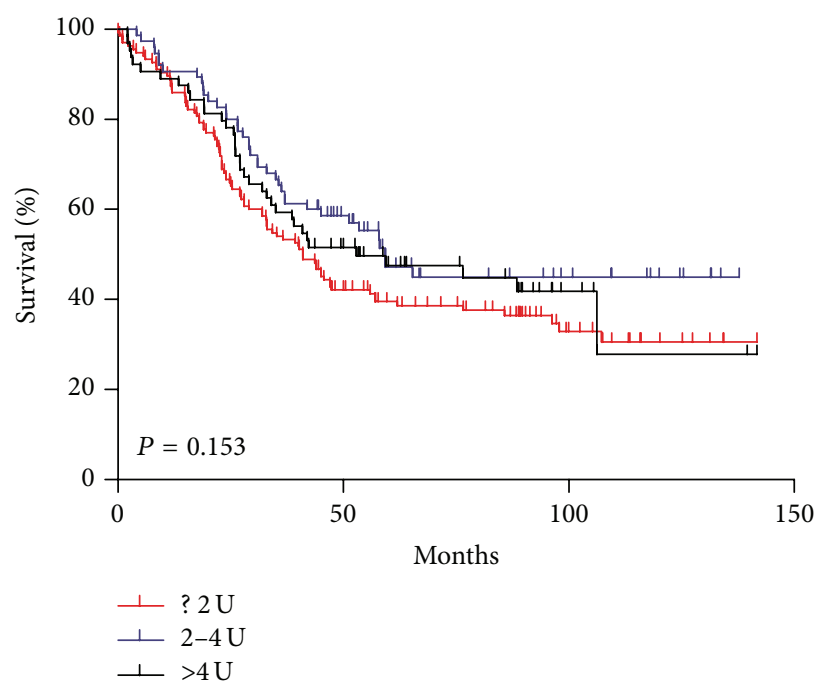

(c)

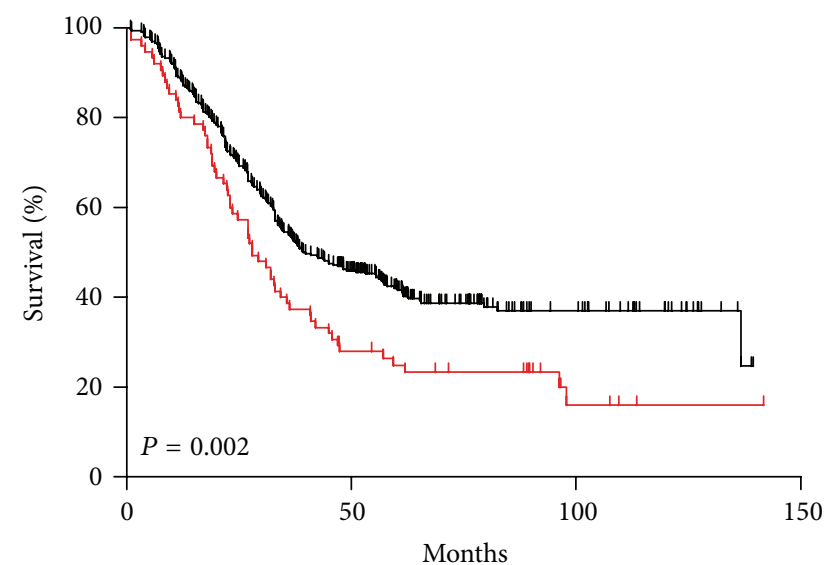

ـ Nontransfused TNM III stage patients with $\mathrm{POHb}>100 \mathrm{~g} / \mathrm{L}$ 1 Transfused TNM III stage patients with POHb $>100 \mathrm{~g} / \mathrm{L}$

(b)

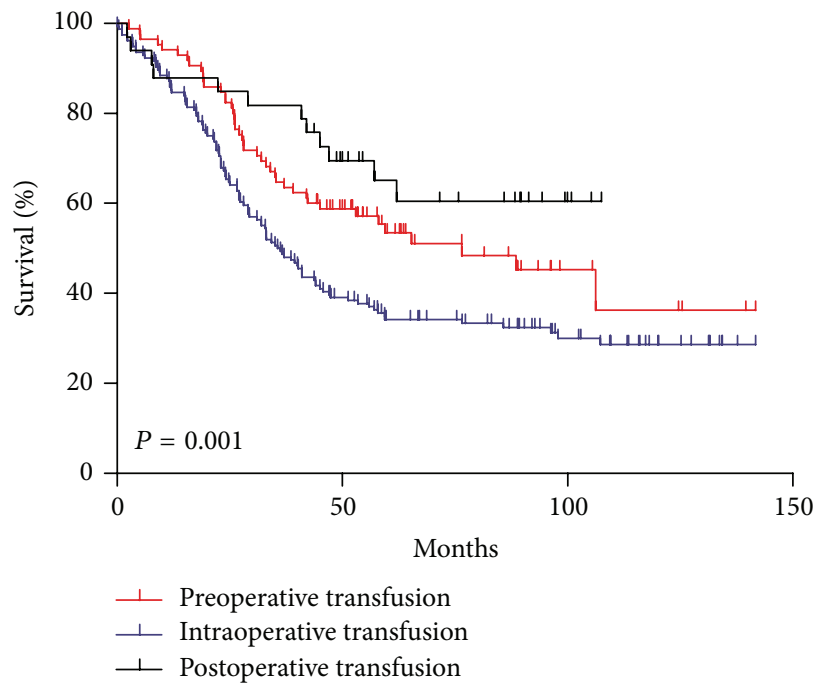

(d)

Figure 2: (a) Survival analysis of transfused and nontransfused TNM I/II stage patients with POHb $>100$ g/L. (b) Survival analysis of transfused and nontransfused TNM III stage patients with POHb $>100 \mathrm{~g} / \mathrm{L}$. (c) Survival analysis of transfused patients with different units of blood. (d) Survival analysis of transfused patients with different transfusion time.

In our study, perioperative blood transfusion resulted in poor prognosis of patients with gastric adenocarcinoma but not an independent prognostic factor. However, this might be influenced by different distributions of clinicopathological features or operation approach between transfused and nontransfused subgroups. When patients were divided according to $\mathrm{POHb}$, we found out that difference was not significant between prognosis of transfused and nontransfused patients with $\mathrm{POHb}$ between 70 and $100 \mathrm{~g} / \mathrm{L}(P=0.191)$. Survival outcome was significantly worse in transfused group than nontransfused group in patients with $\mathrm{POHb}>100 \mathrm{~g} / \mathrm{L}$; however, this difference might be caused by more advanced TNM stage patients in transfused group. Hence, we carried out survival analysis grouped by TNM stage (I/II stage; III stage) in patients with $\mathrm{POHb}>100 \mathrm{~g} / \mathrm{L}$. Distributions were similar with regard to sex, differentiation grade, macroscopic type, and tumor size in both subgroups. We found that transfused TNM III stage patients had worse prognosis than nontransfused patients, while differences were not significant between transfused and nontransfused patients in I/II stage subgroups. We concluded that perioperative blood transfusion contributed to poor prognosis, especially in stage III gastric adenocarcinoma patients.

Blood transfusion may regulate immunity system which may be harmful for patients with cancer. The explanation for the adverse effect of transfusion is probably immunosuppression which may be caused by decreased natural killer cell activity and increased suppressor T lymphocytes activity. Other suppressor factors such as anti-idiotypic antibodies may also be generated after blood transfusion [7, 23]. Heiss 
held the opinion that transfusion might have effect on minimal residual disease in resected-cancer patients which might lead to poor prognosis of them [24]. They witnessed a significant quantitative increase of tumor cells in bone marrow of transfused patients only during follow-up. In advanced stage, immunosuppression caused by transfusion may lead to progression of residual foci and also fail to clear cancer cells in bone marrow. Their finding supported our results that transfused patients had worse prognosis and more postoperative complications such as pulmonary infections, especially in TNM stage III patients.

There were some reports focused on the relationship between prognosis and amount of transfused blood. Hyung's study described significant differences in the prognosis between patients transfused with different units of blood [14]. However, in this study, we revealed that transfused patients with different units of blood did not show significant difference in survival outcomes which was similar to Ojima's and Kanda's results $[15,22]$. Maybe it was transfusion itself which caused immunosuppression and poor prognosis rather than amount of blood transfused. We also found that patients with intraoperative transfusion seemed to have worse survival than preoperative and postoperative transfused patients. Surgical stress inhibited the immune system and might result in immunosuppression which led to poor prognosis of patients with intraoperative blood transfusion [25]. If we cannot avoid perioperative transfusion, we may avoid intraoperative transfusion at least.

This present study, which is one of the largest retrospective researches on Chinese patients, aims to excavate the relationship among $\mathrm{Hb}$ value, transfusion, and prognosis. In patients with $\mathrm{POHb}$ between 70 and $100 \mathrm{~g} / \mathrm{L}$, the difference was not significant between transfused and nontransfused patients. However, in patients with $\mathrm{POHb}>100 \mathrm{~g} / \mathrm{L}$ especially TNM III stage, perioperative blood transfusion related to poor outcomes. Although transfusion did not affect much prognosis of patients with $\mathrm{POHb}$ between 70 and $100 \mathrm{~g} / \mathrm{L}$, blood transfusion still should be avoided for transfused patients who had more postoperative complications. And we also should avoid intraoperative blood transfusion for the adverse effect on prognosis. In our study, intraoperative blood loss was an independent risk factor for transfusion. Thus, as to surgeons, the best method to avoid perioperative transfusion is to reduce intraoperative blood loss, for example, careful anatomical dissection to avoid injury of blood vessels; using some technology or devices to reduce blood loss such as electrocoagulation, ultrasonic, laser devices, and collagen-sealing devices; reducing the length of incision and suture carefully.

Our study is a retrospective study which included 1199 Chinese patients in one center, and we did not analyze the effect of postoperative treatment such as adjuvant chemotherapy or radiotherapy on the long-term survival of our patients in this study. Thus it is necessary to carry out some prospective, randomized, controlled studies to examine the prognostic value of blood transfusion in gastric adenocarcinoma.

In conclusion, perioperative blood transfusion was related to poor prognosis of patients with gastric adenocarcinoma, especially in TNM III stage patients with $\mathrm{POHb}$ $>100 \mathrm{~g} / \mathrm{L}$. Transfused patients also had more postoperative complications than nontransfused ones; thus it is better to refrain from unnecessary perioperative blood transfusion especially intraoperative transfusion.

\section{Conflict of Interests}

The authors declare that there is no conflict of interests regarding the publication of this paper.

\section{Acknowledgments}

The authors thank the substantial work of Volunteer Team of Gastric Cancer Surgery (VOLTGA) based on Multidisciplinary Team (MDT) of Gastrointestinal Tumors, West China Hospital, Sichuan University, China. This work received domestic support from (1) National Natural Science Foundation of China (no. 81372344, no. 81301866); (2) Sichuan Province Youth Science \& Technology Innovative Research Team, no. 2015TD0009.

\section{References}

[1] A. Jemal, F. Bray, M. M. Center, J. Ferlay, E. Ward, and D. Forman, "Global cancer statistics," CA Cancer Journal for Clinicians, vol. 61, no. 2, pp. 69-90, 2011.

[2] Y. Talukder, A. P. Stillwell, S. K. Siu, and Y.-H. Ho, "Comparing survival and recurrence in curative stage I to III colorectal cancer in transfused and nontransfused patients," International Surgery, vol. 99, no. 1, pp. 8-16, 2014.

[3] R. S. Foster Jr., M. C. Costanza, J. C. Foster, and M. C. Wanner, "Adverse relationship between blood transfusions and survival after colectomy for colon cancer," Cancer, vol. 55, no. 6, pp. 11951201, 1985.

[4] B. J. Linder, R. H. Thompson, B. C. Leibovich et al., "The impact of perioperative blood transfusion on survival after nephrectomy for non-metastatic renal cell carcinoma (RCC)," BJU International, vol. 114, no. 3, pp. 368-374, 2013.

[5] N. H. Hyman, R. S. Foster Jr., J. E. DeMeules, and M. C. Costanza, "Blood transfusions and survival after lung cancer resection," The American Journal of Surgery, vol. 149, no. 4, pp. 502-507, 1985.

[6] P. I. Tartter, L. Burrows, A. E. Papatestas, G. Lesnick, and A. H. Aufses Jr., "Perioperative blood transfusion has prognostic significance for breast cancer," Surgery, vol. 97, no. 2, pp. 225-230, 1985.

[7] H. S. Wu and A. G. Little, "Perioperative blood transfusions and cancer recurrence," Journal of Clinical Oncology, vol. 6, no. 8, pp. $1348-1354,1988$

[8] S. A. Müller, A. Mehrabi, N. N. Rahbari et al., "Allogeneic blood transfusion does not affect outcome after curative resection for advanced cholangiocarcinoma," Annals of Surgical Oncology, vol. 21, no. 1, pp. 155-164, 2014.

[9] R. Warschkow, U. Güller, D. Köberle et al., "Perioperative blood transfusions do not impact overall and disease-free survival after curative rectal cancer resection: a propensity score analysis," Annals of Surgery, vol. 259, no. 1, pp. 131-138, 2014.

[10] M. Bortul, L. Calligaris, M. Roseano, and A. Leggeri, "Blood transfusions and results after curative resection for gastric cancer," I Supplementi di Tumori, vol. 2, no. 5, pp. S27-S30, 2003.

[11] F. Sánchez-Bueno, J. A. García-Marcilla, J. M. Pérez-Abad et al., "Does perioperative blood transfusion influence long-term 
prognosis of gastric cancer?" Digestive Diseases and Sciences, vol. 42, no. 10, pp. 2072-2076, 1997.

[12] S. Rausei, L. Ruspi, F. Galli et al., "Peri-operative blood transfusion in gastric cancer surgery: prognostic or confounding factor?" International Journal of Surgery, vol. 11, supplement 1, pp. S100-S103, 2013.

[13] F. Pacelli, F. Rosa, D. Marrelli et al., "Do perioperative blood transfusions influence prognosis of gastric cancer patients? Analysis of 927 patients and interactions with splenectomy," Annals of Surgical Oncology, vol. 18, no. 6, pp. 1615-1623, 2011.

[14] W. J. Hyung, S. H. Noh, D. W. Shin et al., "Adverse effects of perioperative transfusion on patients with stage III and IV gastric cancer," Annals of Surgical Oncology, vol. 9, no. 1, pp. 5-12, 2002.

[15] M. Kanda, D. Kobayashi, C. Tanaka et al., "Adverse prognostic impact of perioperative allogeneic transfusion on patients with stage II/III gastric cancer," Gastric Cancer, 2015.

[16] J. H. Liu and W. C. Lin, Clinical Guideline of Blood Transfusion, People's Military Medical Press, Beijing, China, 1998.

[17] Japanese Gastric Cancer Association, "Japanese classification of gastric carcinoma: 3rd English edition," Gastric Cancer, vol. 14, no. 2, pp. 101-112, 2011.

[18] Japanese Gastric Cancer Association, “Japanese gastric cancer treatment guidelines 2010 (ver. 3)," Gastric Cancer, vol. 14, no. 2, pp. 113-123, 2011.

[19] P. Gascon, N. C. Zoumbos, and N. S. Young, "Immunologic abnormalities in patients receiving multiple blood transfusions," Annals of Internal Medicine, vol. 100, no. 2, pp. 173-177, 1984.

[20] N. Blumberg, D. J. Triulzi, and J. M. Heal, “Transfusion-induced immunomodulation and its clinical consequences," Transfusion Medicine Reviews, vol. 4, supplement 1, no. 4, pp. 24-35, 1990.

[21] S. Moriguchi, Y. Maehara, K. Akazawa, K. Sugimachi, and Y. Nose, "Lack of relationship between perioperative blood transfusion and survival time after curative resection for gastric cancer," Cancer, vol. 66, no. 11, pp. 2331-2335, 1990.

[22] T. Ojima, M. Iwahashi, M. Nakamori et al., "Association of allogeneic blood transfusions and long-term survival of patients with gastric cancer after curative gastrectomy," Journal of Gastrointestinal Surgery, vol. 13, no. 10, pp. 1821-1830, 2009.

[23] M. E. Brunson and J. W. Alexander, "Mechanisms of transfusion-induced immunosuppression," Transfusion, vol. 30, no. 7, pp. 651-658, 1990.

[24] M. M. Heiss, H. Allgayer, K. U. Gruetzner et al., "Prognostic influence of blood transfusion on minimal residual disease in resected gastric cancer patients," Anticancer Research, vol. 17, no. 4, pp. 2657-2661, 1997.

[25] M. Maeta, N. Shimizu, A. Oka et al., "Perioperative allogeneic blood transfusion exacerbates surgical stress-induced postoperative immunosuppression and has a negative effect on prognosis in patients with gastric cancer," Journal of Surgical Oncology, vol. 55, no. 3, pp. 149-153, 1994. 


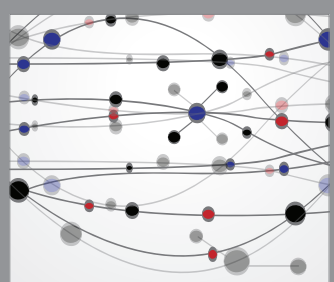

The Scientific World Journal
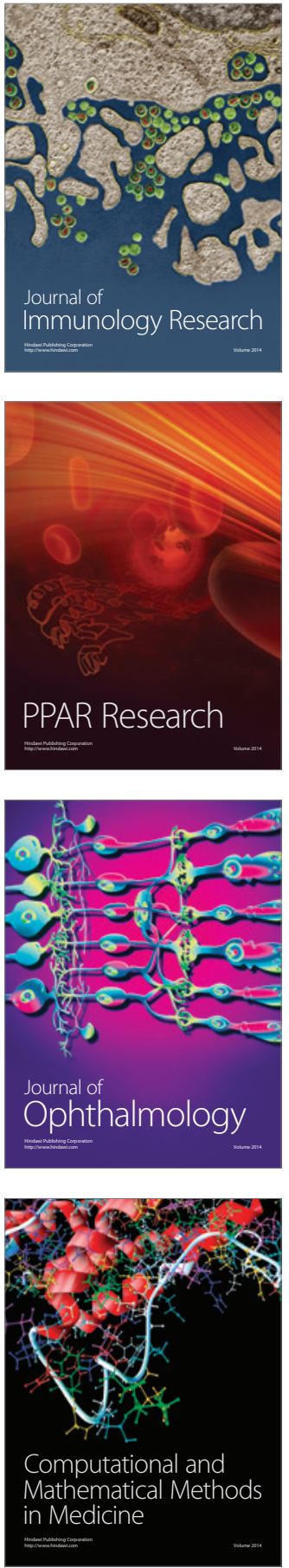

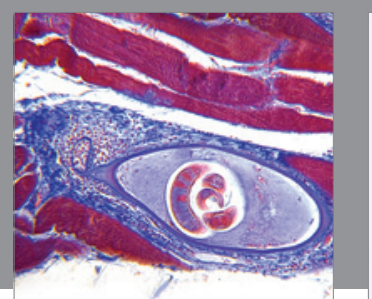

Gastroenterology Research and Practice

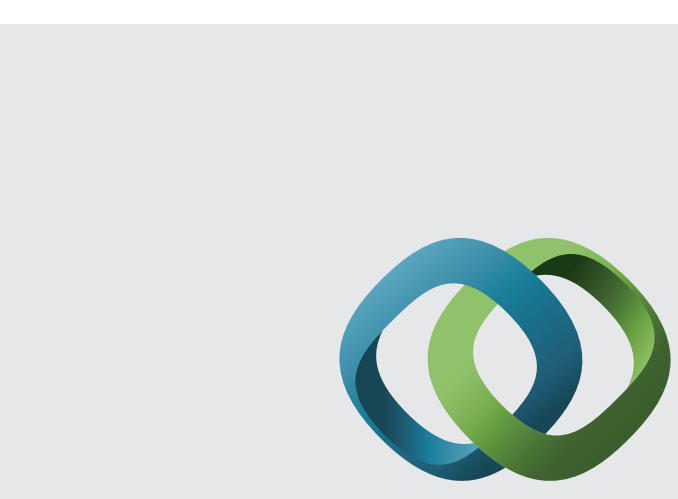

\section{Hindawi}

Submit your manuscripts at

http://www.hindawi.com
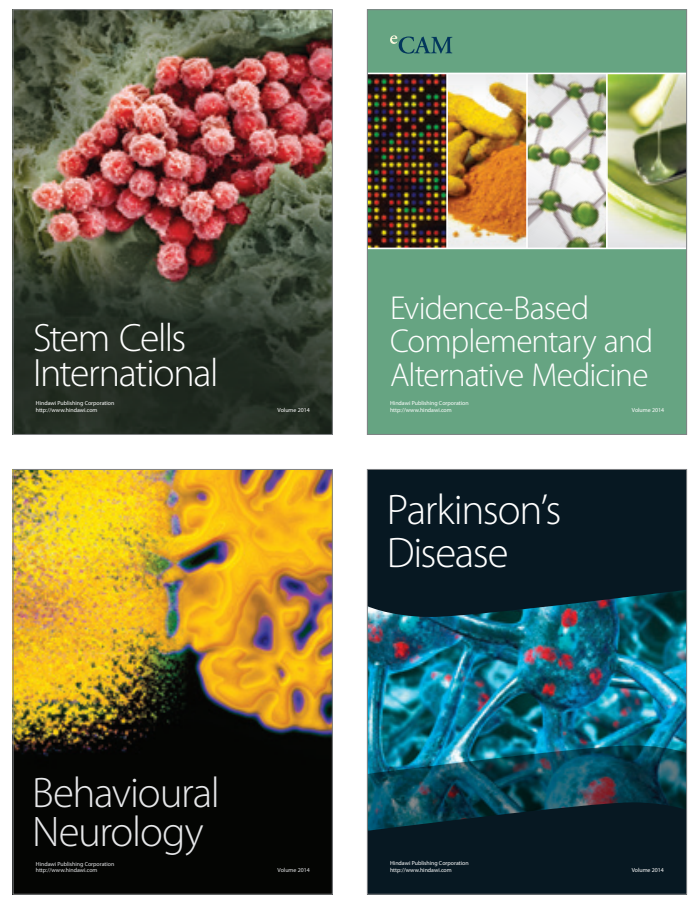
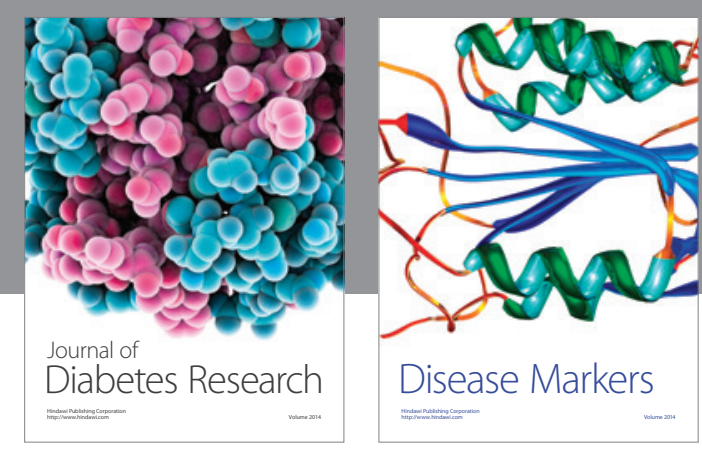

Disease Markers
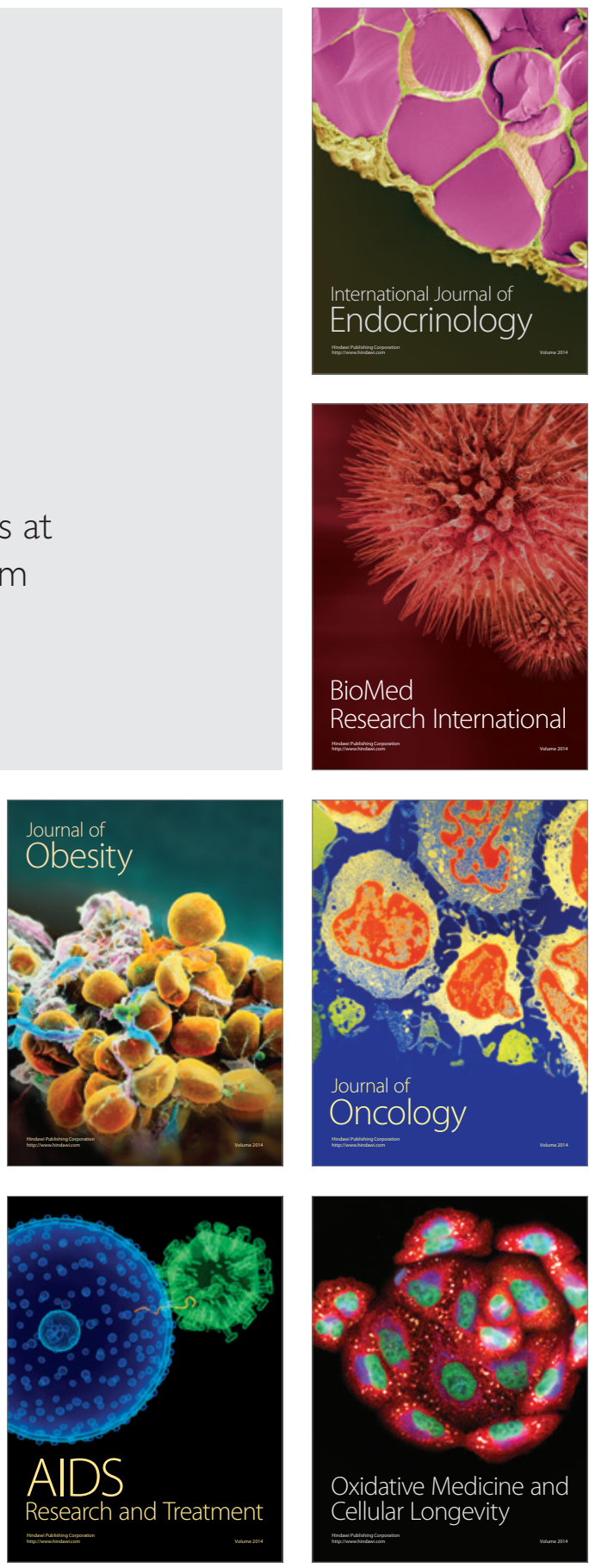